\title{
Intravenous lidocaine as an adjunct to thoraco-lumbar paravertebral block for open appendectomy in children
}

\author{
U. Fesenko', A. Albokrinov'2, V. Perova-Sharonova ${ }^{2}$ \\ ${ }^{1}$ Danylo Galytsky National Medical University in Lviv, Lviv, Ukraine. \\ ${ }^{2}$ Lviv Regional Children's Clinic Hospital "OKHMATDYT", Ukraine
}

Background: Opioid use during anesthesia may cause such adverse events as postoperative nausea/vomiting, delayed recovery, postoperative respiratory depression and others. Regional anesthesia as a sole technique or as a component of combined anesthesia have number of advantages over general anesthesia, particularly in children. Peripheral regional blocks are safer compared to neuraxial ones. Scientific data shows that intravenous lidocaine can cause visceral analgesia and reduce opioid requirements during and after abdominal surgery.

Materials and Methods: Twenty-one 3 to 7 year old children with acute appendicitis were randomized into 2 groups ("Lidocaine", $n=11$ and "Control", $n=10$ ) before open appendectomy. IV induction and maintenance of anesthesia with propofol ( $3 \mathrm{mg} / \mathrm{kg}$ and $6 \mathrm{mg} / \mathrm{kg} \times$ hour respectively), single shot right side thoraco-lumbar paravertebral block (PVB) at T12-L1 level (bupivacaine $0.25 \%, 0.3 \mathrm{ml} / \mathrm{kg}$ ) under local anesthesia and neurostimulation guidance were performed in all children. In children of "Lidocaine" group IV lidocaine 30 minutes before surgery was administered ( $1.5 \mathrm{mg} / \mathrm{kg}$ bolus followed with $1.5 \mathrm{mg} / \mathrm{kg} \times$ hour infusion until the end of surgery). If there was motor or hemodynamic response to surgical stimulation fentanyl boluses $1 \mathrm{mcg} / \mathrm{kg}$ were used in both groups until movements and/or tachycardia/hypertension disappeared.

Results and Discussion: Intraoperative fentanyl dose was significantly lower in "Lidocaine" group compared to "Control" group $(0.4 \pm 0.009 \mathrm{mcg} / \mathrm{kg}$ vs $1.8 \pm 0.011 \mathrm{mcg} / \mathrm{kg}$ respectively, $\mathrm{P}=0.012)$.

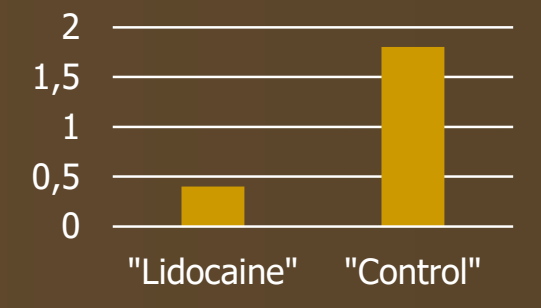

Number of postoperative respiratory depression episodes did not differ between groups ( 0 vs 1 respectively, $\mathrm{P}=0.48$ ).

Postoperative sedation was deeper in "Control" group compared to "Lidocaine" group. Ramsay sedation scores are shown in Table.

\begin{tabular}{|l|c|c|c|c|c|}
\hline & 0 min PO & 10 min PO & 20 min P0 & 30 min PO & 60 min P0 \\
\hline "Lidocaine" group & $3.9 \pm 0.9 * *$ & $2.7 \pm 0.7 * *$ & $1.7 \pm 0.5^{*}$ & $1 \pm 0.3$ & $1 \pm 0.1$ \\
\hline "Control" group & $5.1 \pm 0.8$ & $4.1 \pm 0.4$ & $3.3 \pm 0.6$ & $1.6 \pm 0.2$ & $1 \pm 0.08$ \\
\hline
\end{tabular}

** - $\mathrm{P}<0.01 ; *-\mathrm{P}<0.05$ compared to "Control" group; PO - postoperative.

Children of "Lidocaine" group were discharged from recovery room earlier compared to children of "Control" group, but the difference did not reach statistical significance (19.5 \pm 7.9 vs $28.7 \pm 9.8$ minutes respectively, $\mathrm{P}=0.067)$.

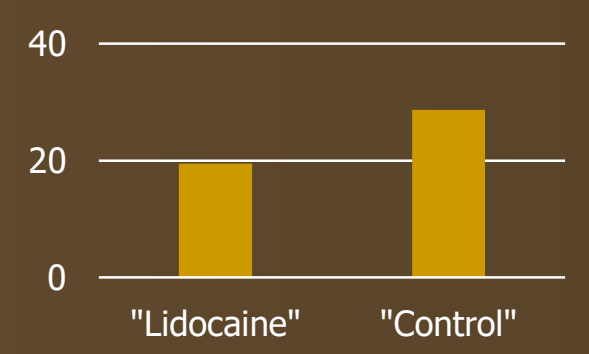

Incidence of postoperative nausea/vomiting (PONV) was lower in "Lidocaine" group compared to "Control" group (0 vs 4 respectively, $\mathrm{P}=0.035)$.

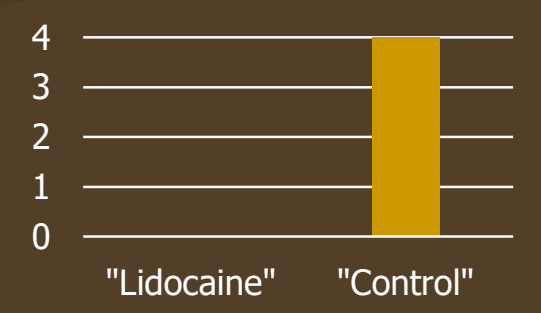

Postoperative opioid dose, NSAIDs dose and pain scores did not differ between groups.

Conclusion: Intraoperative intravenous lidocaine infusion in addition to thoraco-lumbar PVB for appendectomy in children leads to significant intraoperative fentanyl dose reduction and reduces the incidence of opioid related adverse events, such as excessive postoperative sedation, delayed recovery room discharge and PONV. 